\title{
Maternal and fetal outcome in placenta previa: our experience
}

\author{
G. D. Maiti ${ }^{1 *}$, M. Adhikary ${ }^{2}$, P. R. Lele ${ }^{3}$, Shilpa Gupta ${ }^{1}$, M. Saha ${ }^{1}$, Swagata Maiti ${ }^{4}$
}

\begin{abstract}
${ }^{1}$ Department of Obstetrics and Gynecology, Command Hospital (EC), Kolkata, West Bengal, India
${ }^{2}$ Department of Obstetrics and Gynecology, 9 Air Force Hospital, Ludhiana, Punjab, India

${ }^{3}$ Department of Obstetrics and Gynecology, INHS Asvini, Colaba, Mumbai, Maharashtra, India

${ }^{4}$ Department of Dental Surgery, Rajasthan College of Dental Science, Rajasthan, India
\end{abstract}

Received: 20 May 2020

Accepted: 30 June 2020

\section{*Correspondence:}

Dr. G. D. Maiti,

E-mail: gdmaiti@rediffmail.com

Copyright: (C) the author(s), publisher and licensee Medip Academy. This is an open-access article distributed under the terms of the Creative Commons Attribution Non-Commercial License, which permits unrestricted non-commercial use, distribution, and reproduction in any medium, provided the original work is properly cited.

\section{ABSTRACT}

Background: Placenta previa contributes substantial maternal and neonatal morbidity including management challenges for obstetrician. This study was to evaluate the potential risks factors and feto-maternal, outcome in placenta previa. This study was done with the intent of developing insight into risk factors, clinical presentation, various interventions and management for overall improvement in maternal and fetal outcome in placenta previa.

Methods: A prospective observational study, where 30 cases of placenta previa confirmed after 28 weeks POG, treated in a public sector tertiary care hospital from June 2016 to June 2018 were included. Authors analyzed the data to evaluate the potential risks factors and maternal and fetal outcome in placenta previa.

Results: In this study, major contributing risk factors for placenta previa were associated with multiparity (76.7\%), maternal age $>30$ in $50 \%$, previous LSCS in $46.7 \%$, repeated uterine procedure like suction evacuation/curretage. There was a high rate of maternal morbidity mainly due to haemorrhage. Perioperative uterine artery embolization (UAE) in $3(10 \%)$, intra-operative procedures namely devascularization, internal iliac ligation in $66.6 \%$ cases, peripartum hysterectomy in $2(6.66 \%)$ were done to control haemorrhage. Blood and blood products transfusion required in $26.7 \%$ of cases. Fetal morbidity included prematurity in $9(33.3 \%)$, NICU admission in $11(36.6 \%)$ majority of which included $8(26.7 \%)$ babies of birth weight $<2000$ grams.

Conclusions: Placenta previa contributes to significant maternal and neonatal morbidity. Multiparity, post LSCS pregnancy constitute major factor for placenta previa. Management requires high-risk obstetrical care with frequent antenatal visits. Serial ultrasonography in reported cases of low-lying placenta is mandatory to exclude over diagnosis or migration. All cases of placenta previa need to be managed in a higher centre with facility of blood component therapy and neonatal intensive care unit. Prematurity and low birth weight remain a significant cause for neonatal morbidity.

Keywords: Caeserean, Feto-Maternal outcome, Placenta previa

\section{INTRODUCTION}

Placenta previa is a condition where placenta implants in lower uterine segment either very near or covering the internal cervical os. ${ }^{1}$ Placenta previa contributes to one third of all cases of antepartum haemorrhage. Obstetrical haemorrhage remains a leading cause of maternal morbidity and mortality worldwide. An excessive bleeding occurring before or immediately after the birth of a child is dangerous and associated with fatal complication. ${ }^{2}$ The incidence of placenta previa varies from approximately $0.4-0.5 \%$ of all labour. ${ }^{3}$ In developing countries, the contribution of haemorrhage to maternal mortality rates is even more striking and 
obstetrical haemorrhage accounts for almost half of all postpartum deaths. ${ }^{4-6}$ Placenta previa can be a very fearful diagnosis for all caregivers. The period from the diagnosis to the delivery is often clouded with great worry and fear. Due to a the rapidity and extent of haemorrhage, it can lead to life threatening situation for the mother and the fetus.

Placenta previa is an obstetric complication that characteristically occurs in the late second and third trimesters of pregnancy with characteristic painless bleeding per vaginum.

It is also one of the leading causes of antepartum haemorrhage. The condition is associated with significant maternal morbidity and perinatal morbidity and mortality. Availability of blood component, safe anaesthesia, safe caeserean delivery and NICU facility are key factors in improving feto-maternal outcome in placenta previa.

The study was conducted to evaluate risk factors,clinical presentation, feto-maternal complications and outcome with various management in placenta previa.

Aim and objective

- To evaluate demographic and clinical risk factors in cases of placenta previa.

- To evaluate maternal outcome in cases of placenta previa.

- To evaluate fetal outcome in cases of placenta previa.

- To evaluate perinatal mortality and morbidity in placenta previa.

- To evaluate Intervention and management protocols in cases of placenta previa with the objective of improvement in maternal and fetal outcome.

\section{METHODS}

In this prospective observational study, of 30 cases of placenta previa, treated in a public sector tertiary care teaching institute during the period of 2 years from June 2016 to June 2018, were included.

Detailed history, clinical finding investigations and relevant investigation were studied as per the case proforma. Patients attending OPD, IPD and labour room were evaluated thoroughly with clinical history and examination followed by ultrasonography and treated accordingly.

\section{Inclusion criteria}

- All antepartum haemorrhage confirmed by USG as placenta previa after 28 weeks of gestation

- Undiagnosed placenta previa confirmed intraoperatively during caesarean section undertaken for other obstetrical indication
- Patients with clinical and radiological diagnosis of placenta previa at OPD who were otherwise asymptomatic.

\section{Exclusion criteria}

- Second trimester abortions with diagnosis of lowlying placenta before 28 weeks of POG by USG

- Other causes of antepartum haemorrhage.

\section{Diagnostic criteria}

Placenta occupying the lower uterine segment whether partial or completely covering the internal os or having the margin within the $2 \mathrm{~cm}$ from the internal os after 28 weeks of POG.

Gestational age was calculated by the following criteria of which at least 2 have to be fulfilled.

- Date of LMP

- USG dating

- Ultrasonography consistent with dates within before or 28 weeks.

\section{Admission criteria}

- Symptomatic placenta previa with APH-irrespective of POG

- Asymptomatic patient at 37 weeks

- Prior elective termination

- Others obstetrical indications.

On admission, the patient with antepartum haemorrhage with placenta previa was admitted, a detailed history, clinical, obstetrical and sonological examination was done and maternal and fetal condition were assessed.

Further management of the cases were based on the following factors:

- Mother's condition - degree of obstetric hemorrhages - minor and major haemorrhage

- Fetal condition - gestational age, live/dead

- Ability of the neonatal unit to handle an infant of that gestational age.

The obstetric haemorrhage management system of four pillars:

- Communication between all members of the multidisciplinary team

- $\quad$ Resuscitation (as per NRP 2017). ${ }^{7}$

- Monitoring and investigation

- Arrest bleeding by arranging delivery of the fetus.

The RCOG (2016) management strategies - postpartum haemorrhage, prevention and management (Green-top Guideline No. 52) was followed. ${ }^{8}$ 
Measures for PPH followed as per RCOG (2016) GTG52.

Full protocol was followed for major PPH (blood loss greater than $1000 \mathrm{ml}$ ) and continuing to bleed or clinical shock as per institution protocol flowchart (Figure 1).

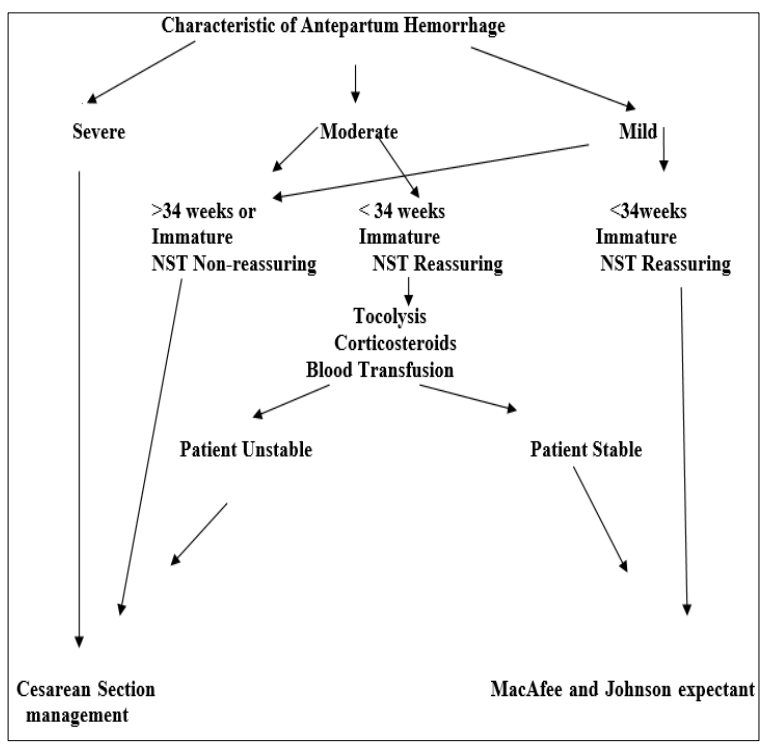

Figure 1: Management protocol of placenta previa.

MacAfee and Johnson expectant management was followed tried for all cases of APH with placenta previa with minor bleeding and fulfilling criteria.

\section{Maternal outcome was measured by}

- Number of transfusions required

- APH severity

- PPH severity

- Operative interventions

- Packing/under running suturing on placental bed

- Uterine artery/internal iliac embolization (UAE)

- Uterine artery ligation

- Internal iliac artery ligation

- Caesarean hysterectomy

- ICU admission

\section{Fetal outcome was measured by}

- Birth weight

- Apgar score

- NICU admission

- $\quad$ POG at birth

In case of fetal death it was documented as fresh stillbirth or macerated stillbirth or neonatal death.

Follow-up of live, viable births was noted till either the mother and/or baby was discharged from the hospital. The fetal and maternal outcome and complications were recorded in each case and the patients and babies assessed at the time of discharge. The duration of hospital stay was recorded in each case.

\section{Statistical analysis}

For statistical analysis, Microsoft excel spreadsheet was used for data collection and analyzed by SPSS 24.0 and GraphPad Prism version 5.

Data were tabulated and summarized as mean and standard deviation for numerical variables and count and percentages for categorical variables A chi-squared test ( $\chi 2$ test), various t-tests were compared, as appropriate.

\section{RESULTS}

As per patient profile, out of total 30 cases, 23 (76.7\%) were multigravida,7 $(23.3 \%)$ were primigravida, and 5 $(16.7 \%)$ were $\leq 25$ years, $10(33.3 \%)$ between $26-30$ years and $15(50.0 \%)$ were $>31$ years of age of which 14 (46.7\%) were post LSCS, 9 (30.0\%) patients had uterine surgery $\mathrm{H} / \mathrm{O}$ of $\mathrm{S}$ and $\mathrm{E}$ and 4 (13.3\%) patients had H/O other surgery (Table 1).

A total $7(23.3 \%)$ patients were anaemic, $6(20.0 \%)$ patients had hypothyroidism, $3(10.0 \%)$ patients had preeclampsia and $3(10.0 \%)$ patients had RH incompatibility (Table 2).

According to types of placenta previa, 9 (30.0\%) patients had low-lying placenta, $20(66.7 \%)$ patients had placenta previa and $1(3.3 \%)$ patient for had placenta previa with accreta. $7(23.3 \%)$ patients had migration of placenta. 9 $(30.0 \%)$ patients had APH.

Table 1: Maternal demography.

\begin{tabular}{|llll|}
\hline \multirow{4}{*}{ Parameter } & & Frequency & Percent \\
\cline { 2 - 4 } & $\leq 25$ & 5 & $16.7 \%$ \\
\cline { 2 - 4 } & $26-30$ & 10 & $33.3 \%$ \\
\cline { 2 - 4 } Parity & $>31$ & 15 & $50.0 \%$ \\
\cline { 2 - 4 } & Multigravida & 23 & $76.7 \%$ \\
\hline \multirow{2}{*}{$\begin{array}{l}\text { H/O } \\
\text { caesarean }\end{array}$} & Primigarvida & 7 & $23.3 \%$ \\
\hline \multirow{2}{*}{ H/O S and E } & No & 16 & $53.3 \%$ \\
\cline { 2 - 4 } & Yes & 14 & $46.7 \%$ \\
\hline \multirow{2}{*}{$\begin{array}{l}\text { H/O any } \\
\text { other surgery }\end{array}$} & No & 21 & $70.0 \%$ \\
\cline { 2 - 4 } & Yes & 4 & $30.0 \%$ \\
\hline
\end{tabular}

Table 2: Distribution of maternal co-morbidity.

\begin{tabular}{|lll|}
\hline Co-morbidity & Frequency & Percent \\
\hline Anemia & 7 & $23.3 \%$ \\
\hline Hypothyroidism & 6 & $20.0 \%$ \\
\hline Pre-eclampsia & 3 & $10.0 \%$ \\
\hline RH incompatibility & 3 & $10.0 \%$ \\
\hline
\end{tabular}


Table 3: Distribution of types of PP, migration and APH.

\begin{tabular}{|c|c|c|c|c|c|}
\hline & & \multirow{2}{*}{\multicolumn{2}{|c|}{$\begin{array}{l}\text { Frequency } \\
\text { Migration }\end{array}$}} & \multirow{2}{*}{ Percentage } & \multirow{2}{*}{ p-value } \\
\hline & & & & & \\
\hline \multirow{6}{*}{ Types of PP } & \multirow{2}{*}{ Low lying placenta } & Yes & 6 & \multirow[b]{2}{*}{$30 \%$} & \multirow{2}{*}{0.15854} \\
\hline & & No & 3 & & \\
\hline & \multirow{2}{*}{ Placenta previa } & Yes & 1 & \multirow{2}{*}{$66.7 \%$} & \multirow{2}{*}{$<0.001$} \\
\hline & & No & 19 & & \\
\hline & \multirow{2}{*}{ Placenta previa and accreta } & Yes & 0 & \multirow{2}{*}{$3.3 \%$} & \multirow{2}{*}{0.1214} \\
\hline & & No & 1 & & \\
\hline \multirow{2}{*}{ APH } & No & 21 & & $70.0 \%$ & \multirow[b]{2}{*}{0.00194} \\
\hline & Yes & 9 & & $30.0 \%$ & \\
\hline
\end{tabular}

Authors found that 6 low in lying placenta had migration in advanced pregnancy whereas 1 in placenta previa group (Table 3).

As regard to location of placenta, 15 (50.0\%) patients had anterior and $15(50.0 \%)$ posterior. According to presentation, $2(6.7 \%)$ patients had breech and 28 (93.3\%) patients had cephalic (Table 4).

\section{Table 4: Distribution of location of placenta} and presentation.

\begin{tabular}{|c|c|c|c|}
\hline & & Frequency & Percentage \\
\hline \multirow{2}{*}{$\begin{array}{l}\text { Location of } \\
\text { placenta }\end{array}$} & Anterior & 15 & $50.0 \%$ \\
\hline & Posterior & 15 & $50.0 \%$ \\
\hline \multirow{2}{*}{ Presentation } & Breech & 2 & $6.7 \%$ \\
\hline & Cephalic & 28 & $93.3 \%$ \\
\hline
\end{tabular}

Table 5: Distribution of POG.

\begin{tabular}{|lll|}
\hline POG & Frequency & Percentage \\
\hline$<34$ & 4 & $13.3 \%$ \\
\hline $34-37$ & 7 & $23.3 \%$ \\
\hline$>37$ & 19 & $63.3 \%$ \\
\hline Total & 30 & $100 \%$ \\
\hline
\end{tabular}

As per the gestational age at presentation/delivery, 4 (13.3\%) patients were <34 POG, 7 (23.3\%) patients 3437 POG and $19(63.3 \%)$ patients were $>37$ weeks of gestation (Table 5).

According to mode of delivery, 11 (36.7\%) patients underwent elective and 14 (46.7\%) had emergency LSCS out of which $3(10.0 \%)$ patients had classical incision, 9 $(30.0 \%)$ patients had intraoperative PPH. $8(26.7 \%)$ patients required blood transfusion including $3(10 \%)$ cases needed massive transfusion (Table 6).

According to intra OP intervention, 4 (13.3\%) patients had B/L UA ligation, $3(10.0 \%)$ patients had B/L UA embolization and ligation, $1(3.3 \%)$ patient had placental bed swinging and $2(6.7 \%)$ patients had peripartum hysterectomy (Table 7).
Table 6: Distribution of mode of delivery and morbidity.

\begin{tabular}{|c|c|c|c|}
\hline & & Frequency & Percentage \\
\hline \multirow{4}{*}{$\begin{array}{l}\text { LSCS/ } \\
\text { Normal }\end{array}$} & $\begin{array}{l}\text { Normal } \\
\text { vaginal }\end{array}$ & 2 & $6.7 \%$ \\
\hline & Elective & 11 & $36.7 \%$ \\
\hline & Emergency & 14 & $46.7 \%$ \\
\hline & Classical & 3 & $10.0 \%$ \\
\hline \multirow{2}{*}{ PPH } & No & 21 & $70.0 \%$ \\
\hline & Yes & 9 & $30.0 \%$ \\
\hline \multirow{3}{*}{$\begin{array}{l}\text { Blood } \\
\text { transfusion }\end{array}$} & No & 22 & $73.3 \%$ \\
\hline & Yes & 8 & $26.7 \%$ \\
\hline & $\begin{array}{l}\text { Massive } \\
\text { transfusion }\end{array}$ & 3 & $10 \%$ \\
\hline
\end{tabular}

Table 7: Distribution of intra-operative intervention/procedure to control haemorrhage.

\begin{tabular}{|lll|}
\hline Intra-OP intervention & Frequency & Percentage \\
\hline B/L UA ligation & 4 & $13.3 \%$ \\
\hline B/L UAE/ligation & 3 & $10.0 \%$ \\
\hline Nil intervention & 20 & $66.7 \%$ \\
\hline Placental bed suturing & 1 & $3.3 \%$ \\
\hline Peripartum hysterectomy & 2 & $6.7 \%$ \\
\hline Total & 30 & $100 \%$ \\
\hline
\end{tabular}

Association of APH and POG at delivery was not statistically significant $(\mathrm{p}=0.1008)$.

Association of birth weight and POG at delivery was statistically significant $(\mathrm{p}=0.0024)$. Association of NICU admission versus POG at delivery was statistically significant $(\mathrm{p}=0.0028)$ (Table 8$)$.

A total $11(36.7 \%)$ patients had NICU Admission. 4 (13.3\%) patients had <34 POG, 7 (23.3\%) patients had 34-37 POG and $19(63.3 \%)$ patients had >37 POG. According to birth weight, $8(26.7 \%)$ patients had $<2000$ gms, 4 (13.3\%) patients had 2001-2500 gms and 18 $(60.0 \%)$ patients had $>2500$ gms. 
Table 8: APH, birth weight and NICU admission.

\begin{tabular}{|c|c|c|c|c|c|c|}
\hline POG & APH & $<34$ weeks POG & 34-37 weeks & $>37$ weeks & Incidence & p-value \\
\hline \multirow{6}{*}{ APH } & \multirow{3}{*}{ No } & 1 & 5 & 15 & 21 & \multirow{6}{*}{0.1008} \\
\hline & & 4.8 & 23.8 & 71.4 & 100.0 & \\
\hline & & 25.0 & 71.4 & 78.9 & 70.0 & \\
\hline & \multirow{3}{*}{ Yes } & 3 & 2 & 4 & 9 & \\
\hline & & 33.3 & 22.2 & 44.4 & 100.0 & \\
\hline & & 75.0 & 28.6 & 21.1 & 30.0 & \\
\hline \multirow{9}{*}{ Birth weight } & \multirow{3}{*}{$<2000 \mathrm{gm}$} & 4 & 3 & 1 & 8 & \multirow{9}{*}{0.0024} \\
\hline & & 50.0 & 37.5 & 12.5 & 100.0 & \\
\hline & & 100.0 & 42.9 & 5.3 & 26.7 & \\
\hline & \multirow{3}{*}{$20001-2500 \mathrm{gm}$} & 0 & 1 & 3 & 4 & \\
\hline & & 0.0 & 25.0 & 75.0 & 100.0 & \\
\hline & & 0.0 & 14.3 & 15.8 & 13.3 & \\
\hline & \multirow{3}{*}{$>2500 \mathrm{gm}$} & 0 & 3 & 15 & 18 & \\
\hline & & 0.0 & 16.7 & 83.3 & 100.0 & \\
\hline & & 0.0 & 42.9 & 78.9 & 60.0 & \\
\hline \multirow{6}{*}{$\begin{array}{l}\text { NICU } \\
\text { admission }\end{array}$} & \multirow{3}{*}{ Yes } & No & 0 & 3 & 16 & \multirow{6}{*}{0.0028} \\
\hline & & Row $\%$ & 0.0 & 15.8 & 84.2 & \\
\hline & & $\mathrm{Col} \%$ & 0.0 & 42.9 & 84.2 & \\
\hline & \multirow{3}{*}{ No } & Yes & 4 & 4 & 3 & \\
\hline & & Row $\%$ & 36.4 & 36.4 & 27.3 & \\
\hline & & $\mathrm{Col} \%$ & 100.0 & 57.1 & 15.8 & \\
\hline
\end{tabular}

Table 9: POG at birth, birth weight and NICU admission.

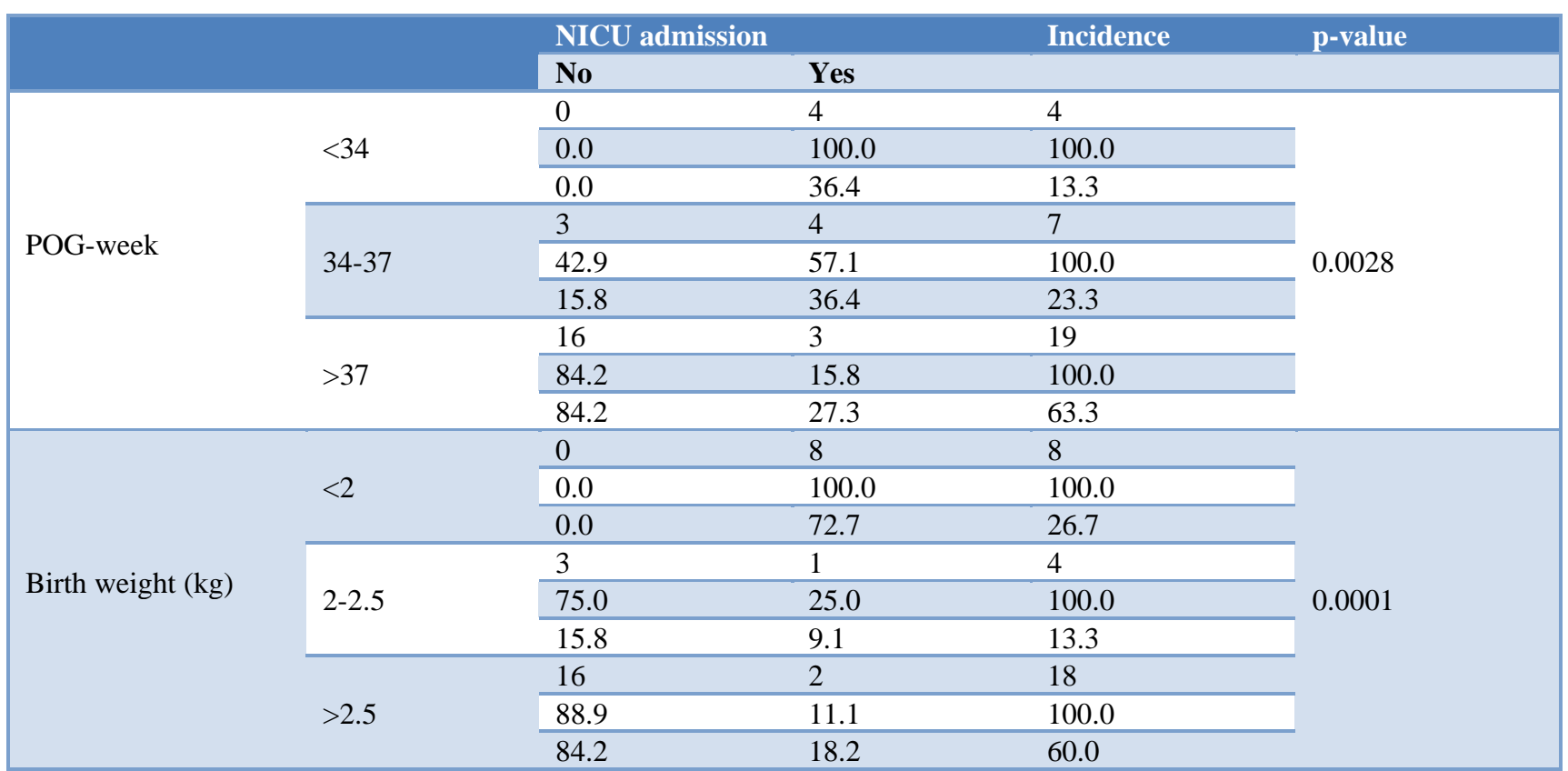

Association of birth weight and POG at delivery was statistically significant ( $\mathrm{p}$ 0.0024). Association of NICU admission and POG at delivery was statistically significant $(\mathrm{p}+0.0028)($ Table 9) .

\section{DISCUSSION}

In the present study, there were 30 cases of placenta previa without any maternal and NBB mortality but associated with significant morbidity. In this study maximum patients $(50 \%)$ were in the age group of $>30$ years of age and $76.7 \%$ women were multiparous woman (Table 1). 14 out of 30 patients of this study (46.7\%) had the previous history of LSCS and 30\% had a history of either MTP or check curettage in their previous pregnancies. $1(3.3 \%)$ case had a history of placenta previa in previous pregnancies. These findings are comparable to the study by Biro $\mathrm{M}$ et al, though 
Babinszki and colleagues reported ' 2.2 per cent incidence in women with parity of 5 or greater and incidence was increased significantly compared with that of women with lower parity. ${ }^{9,10}$ Cesarean delivery for the first pregnancy had a significant 1.6-fold increased risk for previa in the second pregnancy. ${ }^{11}$

In this study $7(23.3 \%)$ patients had anaemia, $6(20.0 \%)$ patients had hypothyroidism, $3(10.0 \%)$ patients had preeclampsia and $3(10.0 \%)$ patients had RH Incompatibility (Table 2).

In this study $9(30.0 \%)$ patients had low lying placenta, $20(66.6 \%)$ patients had placenta previa and $1(3.3 \%)$ patients had placenta previa with accreta at $\geq 28$ weeks of POG (Table 3$) .7(23.3 \%)$ cases had migrated to upper segment. Out 9 low lying placenta, 6 placenta migrated as pregnancy advanced and however only 1 migration occurred in 21 diagnosed placenta previa cases. So, $66.6 \%$ migration occurred in the low-lying placenta and $4.76 \%$ migration occurred in placenta previa. These are consistent to findings by Dashe et al, Laughon et al and Robinson et al. ${ }^{12-14}$ They also concluded that Placentas those lie close to but not over the internal os till early third trimester are unlikely to persist as a previa by term. It is therefore essential for review USG cases of lowlying placenta at 35-37 weeks to reestablish diagnosis.

There was malpresentation in $2(6.7 \%)$ patients i.e., breech on this study while $28(93.3 \%)$ patients had the cephalic presentation and $15(50.0 \%)$ patients had an anterior placenta and $15(50.0 \%)$ posterior placenta (Table 4). At the time of delivery, there was an equal number of anterior and posterior placentas which is similar to findings of Young et al. ${ }^{15}$ In the present study, $9(30 \%)$ cases had APH, out of which 03 cases at $<34$ Wks, 02 cases between $34-37$ Wks and 04 cases presented at $>37$ Wks Table 5).

In this study 9 patients $(30 \%)$ presented with antepartum haemorrhage. MacAfee and Johnson expectant management were tried for all but due to repeat bleeding and/or non-assuring CTG emergency termination were done. Though, $63.3 \%$ of patients of this study were admitted $>37$ weeks of gestation.

In this study $28(93.3 \%)$ patients had caesarean and 2 (6.7\%) patients had vaginal deliveries. Out of 28 caesarean deliveries-3 (10.0\%) patients had classical, 11 $(36.7 \%)$ patients had elective and $14(46.7 \%)$ patients had emergency caesarean section. Similar findings were also seen by Chervenalk et al, who observed $91.7 \%$ caesarean section rate. ${ }^{16}$

A total $9(30.0 \%)$ patients had a postpartum haemorrhage, of which $8(26.7 \%)$ needed blood or blood product transfusion, Out of which $3(10 \%)$ needed a massive transfusion. Similar findings were recorded by Boyle et al, Sabourin et al, where more than half cases had operative haemorrhage and a fourth required blood transfusion (Table 6). ${ }^{17,18}$ In the present study, emergency procedures like, B/L UA ligation was done in 4 (13.3\%), $\mathrm{B} / \mathrm{L}$ UA embolization and ligation in $3(10.0 \%)$, and placental bed suturing in $1(3.3 \%)$.

Caesarean hysterectomy was done in $2(6.7 \%)$ to control acute haemorrhage as a lifesaving measure. In the study by Frederiksen et al, 6\% of women who had a primary cesarean delivery for previa required a hysterectomy and $25 \%$ for women with a previa undergoing repeat cesarean delivery. ${ }^{19}$ Kayem et al, and Penotti et al, reported that only 2 of 33 women with a previa and non-accreta cases where compression sutures failed required a hysterectomy (Table 7)..$^{20,21}$

Neonatal outcome, included, 4 (13.3\%) - early preterm (<34 Wks), 7 (23.3\%)- late preterm $(34-37 \mathrm{Wks})$ and 19 $(63.3 \%)$ babies born were at term (>37 POG). Out of which $8(26.7 \%)$ babies born with $<2000$ grams, 4 (13.3\%) with 2001-2500 grams and 18 (60.0\%) with birth weight $>2500$ grams of birth weight in the present study (Table 8 ). 11 babies (36.66\%) were admitted to NICU for prematurity $9(30.0 \%)$, neonatal jaundice $1(3.3 \%)$, birth asphyxia 1 (3.3\%). All baby had a favorable outcome. Association of POG at delivery versus NICU admission was statistically significant (p 0.0028).

Association of birth weight versus NICU admission was also statistically significant (p 0.0001). Preterm delivery continues to be a major cause of perinatal death as per study by NØrgaard et al and Salihu et al, reported a threefold increased neonatal mortality rate with placenta previa that was caused primarily from preterm delivery (Table 9). ${ }^{22,23}$

Limitations of the study was, sample size is small to extrapolate its statistical conclusion. There are confounding factors in the form of obstetrical and medical complications in the patients with placenta previa which may be independent reasons for aggravating maternal and foetal morbidity.

\section{CONCLUSION}

In this study, major contributing risk factors for placenta previa were multiparity $(76.7 \%)$, age- $50 \%$ (>30 years) and previous LSCS- $46.7 \%$ or multiple uterine procedure like $\mathrm{D}$ and $\mathrm{E} / \mathrm{D}$ and $\mathrm{Cs}$.

A number of total 30 cases of placenta previa were associated with significant morbidity which is mostly due to haemorrhage. Various conservative intra/peri-operative procedures like UA ligation, internal iliac ligation, UA embolization, placental bed suturing etc in 8 (26.6\%) cases, blood and blood products transfusion were done in $26.7 \%$ of cases including $3(10 \%)$ massive transfusion to deal with acute blood loss. $2(6.6 \%)$ cases required caesarean hysterectomy as a life-saving procedure. 
Prematurity and low birth weight due to unavoidable early termination remain major cause as the of neonatal morbidity requiring to NICU admission of which 11 $(36.66 \%)$ neonates including $8(26.7 \%)$ babies were of birth weight $<2000$ grams.

Authors therefore suggest that all cases of placenta previa require high-risk obstetrical care with frequent antenatal visits and serial obstetrical ultrasonography. Cases reported to be low lying placenta in second trimester need to be confirmed at third trimester as number of placental migrations were noted in the study. All cases of placenta previa should be managed at centre having blood component therapy and neonatal intensive care unit.

\section{Funding: No funding sources}

Conflict of interest: None declared

Ethical approval: The study was approved by the Institutional Ethics Committee

\section{REFERENCES}

1. Elsayes KM, Trout AT, Friedkin AM, Liu PS, Bude RO, Platt JF, et al Imaging of placenta: a multimodality pictorial review. Radiograph. 2009;29(5):1371-91.

2. Williams text book of obstetrics. $24^{\text {th }}$ Edition, Obstetrical haemorrhage; 2014:780.

3. Crane JM, Van den Hof MC, Dodds L, Armson BA, Liston R. Maternal complication with placenta previa. Am J Perinatol. 2000;17(2):101-5.

4. Cunningham FG, Leveno KJ, Bloom SL, Hauth JC, Rouse DJ, Spong C. Williams Obstetrics. McGraw-Hill. New York; 2018: 755.

5. Lalonde A, Daviss BA, Acosta A, Herschderfer K. Postpartum haemorrhage today: ICM/FIGO initiative 2004-2006. Int J Obstet Gynaecol. 2006;94:243.

6. McCormick ML, Sanghvi $\mathrm{HC}$ and McIntosh $\mathrm{N}$ : Preventing postpartum haemorrhage in low-resource settings. Int J Gynaecol Obstet. 2002;77:267.

7. Weiner GM. Textbook of Neonatal Resuscitation. American Academy of Pediatrics, $7^{\text {th }}$ Edition; 2016:17.

8. Mavrides E, Allard S, Chandraharan E, Collins P, Green L, Hunt BJ, et al. On behalf of the Royal College of Obstetricians and Gynaecologists. Prevention and management of postpartum haemorrhage. BJORG. 2016;124.

9. Biro MA, Davey MA, Carolan M, Kealy M. Advanced maternal age and obstetric morbidity for women giving birth in Victoria, Australia: a population-based study. Aust N Z J Obstet Gynaecol. 2012;52(3):229.

10. Babinski A, Kerenyi T, Torok O, Grazi V, Lapinski $\mathrm{RH}$, Berkowitz RL. Perinatal outcome in grand and great grand multiparity: effects of parity on obstetric risk factors. Am J Obstet Gynecol, 1999; 81:669.

11. Gurol-Urganci I, Cromwell DA, Edozien LC, Smith GC, Onwere C, Mahmood TA. Risk of placenta previa in second birth after first birth cesarean section. BMC Preg Childbirth. 2011;11:95.

12. Dashe JS, McIntire DD, Ramus RM, Santos-Ramos R, Twickler DM. Persistence of placenta previa according to gestational age at ultrasound detection. Obstet Gynecol. 2002;99:692.

13. Laughon SK, Wolfe HM, Visco AG. Prior cesarean and the risk for placenta previa on second-trimester ultrasonography. Obstet Gynecol. 2005;105:962.

14. Robinson AJ, Muller PR, Allan R, Ross R, Baghurst PA, Keirse MJ. Precise mid-trimester placenta localisation: does it predict adverse outcomes? Aust N Z J Obstet Gynaecol. 2012;52(2):156.

15. Young B, Nadel A, Panda B, Kaimal A. Does placenta previa location matter? Surgical morbidity associated with previa location. Am J Obstet Gynecol. 2013;208(1):S57

16. Chervenak F, Lee Y, Hendler M. Role of attempted vaginal delivery-management of placenta praevia. Obstet Gynaecol. 1984;64(6):798-801.

17. Boyle RK, Waters BA, O'Rourke PK: Blood transfusion for caesarean delivery complicated by placenta praevia. Aust N Z J Obstet Gynaecol. 2009;49(6):627.

18. Sabourin JN, Lee T, Magee LA, von Dadelszen P, Demianczuk N. Indications for, the timing of, and modes of delivery in a national cohort of women admitted with antepartum haemorrhage at $22+0$ to $28+6$ weeks' gestation. J Obstet Gynaecol Can. 2012;34(11):1043.

19. Frederiksen MC, Glassenberg R, Stika CS. Placenta previa: a 22-year analysis. Am J Obstet Gynecol. 1999; $180: 1432$.

20. Kayem G, Kurinczuk JJ, Alfirevic Z, Spark P, Brocklehurst $\mathrm{P}$, Knight M. Uterine compression sutures for the management of severe postpartum haemorrhage. Obstet Gynecol. 2011;117(1):14.

21. Penotti M, Vercellini P, Bolis G. Compressive suture of the lower uterine segment for the treatment of postpartum haemorrhage due to complete placenta previa: a preliminary study. Gynecol Obstet Invest. 2012;73(4):314.

22. NØrgaard LN, Pinborg A, Lidegaard Ø, Bergholt T. A Danish national cohort study on neonatal outcome in singleton pregnancies with placenta previa. Acta Obstet Gynecol Scand. 2012;91(5):546.

23. Salihu HM, Li Q, Rouse DJ, Alexander GR. Placenta previa: neonatal death after live births in the United States. Am J Obstet Gynecol. 2003;188:1305.

Cite this article as: Maiti GD, Adhikary M, Lele PR, Gupta S, Saha M, Maiti S. Maternal and fetal outcome in placenta previa: our experience. Int J Reprod Contracept Obstet Gynecol 2020;9:3253-9. 